\title{
Assessment of Small Dense Low-Density Lipoprotein and Apolipoprotein B/Apolipoprotein A-I Ratio to Predict the Peripheral Arterial Disease in Patients with Hypertension
}

\author{
Kurniawan Prihutomo, MID. Pramudianti, Amiroh Kurniati \\ Department of Clinical Pathology, Faculty of Medicine, Sebelas Maret University/Dr. Moewardi General Hospital, Surakarta, Indonesia. \\ E-mail:kurniawan_prihutomo@yahoo.com
}

\begin{abstract}
Small Dense Low-Density Lipoprotein (sdLDL) and the ApoB/ApoA-I ratio has greater atherogenic potential and is a better marker to predict atherosclerotic blood vessel disease. The purpose of this study was to determine the relationship between the sdLDL and ApoB/ApoA-I ratio to assess the prevalence risk of Peripheral Arterial Disease (PAD) in hypertensive patients. A cross-sectional observational analytic study was performed in 51 hypertension patients with age > 18 years old in Dr. Moewardi Hospital Surakarta from May until June 2018. Patients have measured ABI scores, BMI, blood pressure, lipid profile, ApoB, and ApoA levels. Data were statistically analyzed was using bivariate analysis and multivariate analysis. $\mathrm{P}$-value $<0.05$ was statistically significant. The prevalence of PAD was $54.90 \%$. Bivariate analysis of age variables (PR: $3.15 ; 95 \% \mathrm{Cl}$ : 1.128-8.811; $p=0.005)$, sdLDL (PR: 2; 95\% Cl: 0.997-4.013; $p=0.03$ ), the ratio of ApoB/ApoA-I (PR: 5.786; 95\% Cl: 0.899-37.224; $\mathrm{p}=0.007$ ), and smoking (PR: 1.896; 95\% Cl: 1.210-2.971; $\mathrm{p}=0.015)$ was significantly related with PAD. After adjustment of age, smoking, and dyslipidemia variables using multivariate logistic regression analysis, PAD was still related with sdLDL (PR: 10.55; 95\% CI: 1.80-61.73; $p=0.009$ ), age (PR: 11. 61; 95\% CI: 1.83-61.73; $p=0.009$ ), and smoking (PR: 11.96; 95\% CI: 1.71-83.81; $p=0.013)$. sdLDL and ApoB/ApoA-I ratio were related to PAD. However, sdLDL, age, and smoking are independent variables of PAD in hypertension patients.
\end{abstract}

Keywords: sdLDL, ApoB/ApoA-I ratio, peripheral arterial disease, hypertension

\section{INTRODUCTION}

Hypertension is defined as Systolic Blood Pressure (SBP) of $\geq 140 \mathrm{mmHg}$ and/or Diastolic Blood Pressure (DBP) of $\geq 90 \mathrm{mmHg}$. Hypertension causes hemodynamic force, thrombocyte activation, fibrinolysis, endothelial cell dysfunction, and abnormal levels of the hemostatic factor. Increased oxidative stress generally occurs in hypertension and hyperlipidemia that may produce an inflammatory response and in the presence of hyperlipidemia leads to the formation of atherosclerotic plaques. ${ }^{1,2}$

Peripheral Arterial Disease (PAD) is a narrowing or blockage of the arteries which supply blood to the lower limbs mainly due to atherosclerosis. Peripheral arterial disease is a major cause of morbidity because of functional decline and loss of limbs. The risk factors of PAD are Diabetes Mellitus (DM), obesity, smoking, old age, dyslipidemia, and hypertension. Patients with PAD have increased risk of Myocardial Infarction (MI), stroke and death. ${ }^{3-6}$

Peripheral artery disease and hypertension are related diseases, and approximately $35-55 \%$ of PAD patients also have hypertension. The prevalence of PAD in hypertension patients in China is around $8.7 \%$, while in Indonesia is $9.7 \%$. According to the study of the American Society of Cardiology (ASC) in 2006, Indonesia was included as a research subject among 24 countries. Data on the prevalence of other PADs were obtained from a study of many countries by PAD-search in which Indonesia is also one of the study subjects. Every one million Indonesians, 13807 of them suffer from PAD. ${ }^{3,7,8}$

Angiography is a gold standard for assessing the severity, the site, and the extent of PAD; however, it is not routinely used because of its invasiveness and complications. Digital examination Subtraction Angiography (DSA) and Computed Tomography Angiography (CTA) are expensive and have contrast media side effects. Therefore, a simple yet accurate non-invasive assessment of LAP is essential for diagnostic purposes. The Ankle-Brachial Index (ABI) is one of the examination methods to diagnose PAD. Ankle brachial index is a non-invasive, inexpensive, and more accessible diagnostic method for diagnosing PAD with a sensitivity of $90 \%$ and a 
specificity of $98 \%$. Patients were considered to have arterial insufficiency when ABI score $<1$, whereas normal patients had an ABI score of $\geq 1.9 .10$

Small dense low-density lipoprotein has been reported to have greater atherogenic potential than other Low-Density Lipoprotein (LDL) subfractions and is a better marker for predicting atherosclerotic vascular disease. Increased atherogenicity of sdLDL is related to the specific biochemical and biophysical properties of these particles. The sdLDL particles are considered to be highly atherogenic due to the smaller particle size enabling higher penetration of the arterial wall, causing lower binding affinity for LDL receptors, longer plasma half-life, and lower resistance to oxidative stress compared to LDL. Trapped and accumulated lipids by foam cells in the arterial wall are the main processes leading to the development of atherosclerotic plaques. Oxidation in blood plasma is one of the first atherogenic modifications of LDL particles. The oxidation process produces specific oxidation in LDL particles which induces an immune response and inflammation. Currently, available laboratory methods for the sdLDL test are ultracentrifugation, Gradient Gel Electrophoresis (GGE), and Nuclear Magnetic Resonance (NMR). All of them relatively difficult, less efficient and require complex equipment. Equations derived from classical lipid parameters can be used as an alternative method to calculate sdIDL. The $L D L / A p o B$ ratio represents $L D L$ particle size, and the ratio $<1.2$ (LDL particle size $25.5 \mathrm{~nm}$ or smaller) indicates the presence of sdLDL. Jacomella et al. (2014) reported that sdLDL was related to worse initial outcomes in patients undergoing percutaneous revascularization of symptomatic PAD. The proportion of sdLDL (class III and IV) was significantly lower $(33.1611 .0 \%$ vs. $39.4612 .1 \%$, $\mathrm{p}=0.038$ ) in patients who showed improvement compared to those who did not. ${ }^{11-15}$

The ApoB/ApoA-I ratio represents the balance between atherogenic and anti-atherogenic lipoproteins in the plasma. Several clinical and epidemiological studies have confirmed that the ApoB/ApoA-I ratio is a superior marker for cardiovascular disease compared to lipids and lipoproteins or their ratios. Recent studies show that the use of conventional lipid indices can cause errors in cardiovascular risk assessment. $A p o B$ is an atherogenic lipoprotein particle and it contributes to primarily increased retention of $L D L$ in the vascular subendothelial. Increased $A p o B$ concentration is associated with the formation of higher atherosclerotic plaques. ApoA-I is a major apolipoprotein in HDL particles, covering $70 \%$ as an anti-atherogenic substance. High-density heterogeneous lipoproteins vary greatly in composition and size in each patient. Also, ApoA-I is potentially more accurate than $\mathrm{HDL}$ to reflect the potential for atheroprotective lipid metabolism. ${ }^{16-18}$ Research by Lima et al. obtained a strong positive correlation between ApoB/ApoA-I ratio and $A p o B$ in 30 patients with $\operatorname{PAD}(r=0.91 ; p<0.0001){ }^{19}$

\section{METHODS}

The study was performed in 51 hypertensive patients who came to the Cardiology Outpatient Clinic of Dr.Moewardi Hospital and underwent laboratory examinations at the Clinical Pathology Installation between May 2018-June 2018. The inclusion criteria were patients with a diagnosis of hypertension examined by $\mathrm{ABI}$ and examination at the Clinical Pathology laboratory, adult patients $>18$ years old willing to participate in the research by signing informed consent. Patients with diabetes, impaired liver function, trauma history, surgery, or amputation involving a lower limb, foot ulcer, and incomplete medical record data were excluded from this study.

At admission, all the subjects underwent a medical examination and filled a questionnaire on personal and medical items, including age, past medical history, and use of medications. Hypertension (systolic > 140 or diastolic blood pressure $>90 \mathrm{mmHg}$, or pharmacological therapy with antihypertension drugs), and smoking habits were recorded. Additionally, height and weight were recorded and body mass index (BMI) was calculated as $\mathrm{kg} / \mathrm{m}^{2}$. The $A B I$ was defined $\geq 1$. Obesity was defined as BMI $>30 \mathrm{~kg} / \mathrm{m}^{2}$.

All samples were used for examination of lipid profiles (TC, HDL, LDL, TG) and measured with IL Taurus chemical automatic analyzer. The ApoB, ApoA-I were measured with ApoBApoB-I Auto $N$ "Daiichi" reagent kit using a TMS 24i Platinum chemical analyzer with a method of turbidimetric immunoassay (TIA), and SdLDL was determined by LDL measurement and ApoB (indirect) parameters.

The subjects were diagnosed with dyslipidemia if one of the results obtained from the four examination parameters TC, HDL, LDL, TG was not in the normal value of each examination.

Statistical analysis for comparisons was performed by using paired T-test (for normal data) and Mann-Whitney test (for abnormal data). Bivariate analysis using crosstab and multivariate analysis was performed by logistic regression to assess possible clinical and laboratory variables 
independently associated with the presence of PAD.

Research permission was obtained from the Health Research Ethics Committee of the Sebelas Maret University/Dr. Moewardi Hospital, Surakarta with number 587/VI/HREC/2018.

\section{RESULTS AND DISCUSSION}

The research subjects consisted of 24 (47.1\%) male patients and 27 (52.9\%) female patients. The mean age of patients was 63 (31-76) years, with 37 (72.5\%) subjects $\geq 55$ years old and $14(27.4 \%)<55$ years old. Average $\pm S D$ or middle value (25th percentile 75) SBP, DBP, BMI, TC, HDL, LDL, and TG levels of the subjects of this study were $151.88 \pm 2.63$; $82.94 \pm 2.01 ; 25.68 \pm 0.69 ; 178.63 \pm 5.46 ; 45.31 \pm 1.45$; $2.02 \pm 0.01$; and $2.12 \pm 0.02$, respectively. According to BMI parameters there were 4 (7.8\%) underweight, 21 (41.2\%) normal, 19 (37.3\%) overweight, and 7 (13.7\%) obese subjects (Table 1 ).

The mean SBP, DBP, TC, HDL, LDL, and TG levels were higher in the PAD-free hypertension group than in the hypertension group with PAD. Gender and age were significantly different in hypertension with PAD and non-PAD groups $(p=0.000$ and $p=0.013)$, while other parameters such as SBP, DBP, TC, HDL, LDL, and TG showed no significant differences $(p=0.72 ; p=0.31 ; p=0.20 ; p=0.17 ; p=0.06$; and $\mathrm{p}=0.86$ ) (Table 2).

Bivariate analysis results of age, sdLDL, the ratio of ApoB/ApoA-I, and smoking were as follows:(PR: 3.15; 95\% Cl: 1.128-8.811; $p=0.005),(P R: 2 ; 95 \% ~ C l:$ 0.997-4.013; $\quad p=0.03), \quad(P R: 5.786 ; 95 \% \quad C l:$ $0.899-37.224 ; p=0.007)$, and (PR: 1.896; 95\% Cl: 1.210-2.971; $p=0.015)$, respectively. The result of multivariate analysis of regression on age, smoking, and dyslipidemia variables, sdLDL showed relation with PAD incidence, with PR of 10.55 (95\% CI: 1.80-61.73; $p=0.009$ ), age with PR of 11.61 (95\% CI: 1.83-61.73; $p=0.009)$, and smoking with PR was 11.96 (95\% CI: 1.71-83.81; $p=0.013$ ), while other variable showed no significant relation with PAD incidence in hypertensive patients (Table 3 ).

Patients with PAD have higher concentrations of sdLDL. Jacomella et al. reported that increased sdLDL concentrations were obtained in patients with poor initial results after the angioplasty procedure, the presence of large numbers of sdLDL particles was a negative predictor for the success of peripheral angioplasty. ${ }^{20}$ A study by Li et al. further confirmed that sdLDL is a better lipid variable than other cholesterol ratios to predict arterial stiffness. ${ }^{21}$

This study findings were similar to the study by Johansson and Schmidt. There was a 3-fold increased risk of PAD occurrence for 8.9 years of follow-up with a cut-off ratio of ApoB/ApoA-I > 0.63,

Table 1. Basic characteristics of research subjects

\begin{tabular}{|c|c|c|c|c|}
\hline Variable & Total (n) & $\begin{array}{c}\text { Hypertension } \\
\text { without PAD (n ) }\end{array}$ & $\begin{array}{l}\text { Hypertension } \\
\text { with PAD (n ) }\end{array}$ & $\mathbf{p}$ \\
\hline \multicolumn{5}{|l|}{ Gender } \\
\hline Male & $24(47.1 \%)$ & $4(7.8 \%)$ & 20 (39.3\%) & $0.0001^{*}$ \\
\hline Female & 27 (52.9\%) & 19 (37.3\%) & $8(15.6)$ & \\
\hline \multicolumn{5}{|l|}{ Age (years) ${ }^{b}$} \\
\hline$\geq 55$ years & 37 (72.5\%) & 12 (23.5\%) & 25 (49\%) & $0.013^{*}$ \\
\hline$<55$ years & 14 (27.4\%) & 11 (21.6\%) & $3(5.9 \%)$ & \\
\hline $\operatorname{SBP}(\mathrm{mmHg})^{\mathrm{a}}$ & $151.88 \pm 2.63$ & $152.91 \pm 4.29$ & $151.04 \pm 3.30$ & 0.72 \\
\hline $\mathrm{DBP}(\mathrm{mmHg})^{\mathrm{a}}$ & $82.94 \pm 2.01$ & $85.17 \pm 3.35$ & $82.87 \pm 2.57$ & 0.31 \\
\hline $\mathrm{TC}(\mathrm{mg} / \mathrm{dL})^{\mathrm{a}}$ & $178.3 \pm 5.46$ & $186.26 \pm 9.15$ & $171.87 \pm 6.97$ & 0.20 \\
\hline $\mathrm{HDL}(\mathrm{mg} / \mathrm{dL})^{\mathrm{a}}$ & $45.1 \pm 1.45$ & $47.52 \pm 1.79$ & $45.09 \pm 2.42$ & 0.17 \\
\hline $\operatorname{LDL}(\mathrm{mg} / \mathrm{dL})^{\mathrm{b}}$ & $100(53-204)$ & $114(53-2014)$ & $97(62-165)$ & 0.06 \\
\hline $\mathrm{TG}(\mathrm{mg} / \mathrm{dL})^{\mathrm{b}}$ & $132(47-314)$ & $135(80-240)$ & $132(47-314)$ & 0.86 \\
\hline \multicolumn{5}{|l|}{$\mathrm{BMI}^{\mathrm{a}}$} \\
\hline Underweight & $4(7.8 \%)$ & $3(5.9 \%)$ & 1 (1.9\%) & - \\
\hline Normal & 21 (41.2\%) & 8 (15.7\%) & $13(25.5 \%)$ & - \\
\hline Overweight & 19 (37.3\%) & 8 (15.7\%) & 11 (21.6\%) & - \\
\hline Obese & 7 (13.7\%) & $4(7.8 \%)$ & $3(5.9 \%)$ & - \\
\hline
\end{tabular}

a: normal data distribution (mean \pm SD), different test with independent T-test, $p<0.05$ significant. b: abnormal data distribution [mean value (25-75 percentile)] with the Mann-Whitney $U$ test, $p<0.05$ is significant. SBP: Systolic Blood Pressure; DBP: Diastolic Blood Pressure; TC: Total Cholesterol; HDL: High-Density Lipoprotein; LDL: Low-Density Lipoprotein; TG: triglycerides; BMI: Body Mass Index; mg: Milligram; dL: Decilitre; mmHg: Millimetre of Mercury. ${ }^{\mathrm{p}}<0.05$ significant 
Table 2. $2 \times 2$ test table between $s d L D L, A p o B / A p o A-I$ ratio and other variables that might influence the incidence of PAD in hypertension patients

\begin{tabular}{|c|c|c|c|c|}
\hline \multirow[b]{2}{*}{ Variable } & \multicolumn{2}{|c|}{ Hypertension with PAD } & \multirow[b]{2}{*}{ PR (95\%CI) } & \multirow[b]{2}{*}{$\mathbf{p}$} \\
\hline & Yes & No & & \\
\hline \multicolumn{5}{|l|}{ Age (years) } \\
\hline$\geq 55$ years & 25 & 12 & $3.15(1.128-8.811)$ & $0.005^{*}$ \\
\hline$<55$ years & 3 & 11 & & \\
\hline \multicolumn{5}{|l|}{ sdLDL } \\
\hline$<1.2$ & 22 & 11 & $2(0.997-4.013)$ & $0.03^{*}$ \\
\hline$\geq 1.2$ & 6 & 12 & & \\
\hline \multicolumn{5}{|c|}{ ApoB/ApoA-I ratio } \\
\hline$\geq 0.9$ & 27 & 15 & $5.7(0.89-37.22)$ & $0.007^{*}$ \\
\hline$<0.9$ & 1 & 8 & & \\
\hline \multicolumn{5}{|c|}{ Dyslipidemia } \\
\hline Yes & 17 & 12 & $1.17(0.69-1.96)$ & 0.58 \\
\hline No & 11 & 11 & & \\
\hline \multicolumn{5}{|l|}{ Smoking } \\
\hline Yes & 13 & 3 & $1.89(1.21-2.97)$ & $0.015^{*}$ \\
\hline No & 15 & 20 & & \\
\hline
\end{tabular}

Prevalence ratio was calculated by the formula $a /(a+b): c /(c+d)$

Description: PAD: Peripheral Artery Disease, PR: Prevalence Ratio, CI: Confidence Interval, Apo: Apolipoprotein; sdLDL: Small Dense Low-Density Lipoprotein. * $p<0.05$ significant

Table 3. Multivariate analysis results of logistic regression sdLDL and ratio of ApoB/ApoA-I and other variables affecting PAD incidence in hypertensive patients

\begin{tabular}{cccc}
\hline \multicolumn{1}{c}{ Variable } & PR & $\mathbf{9 5 \% C I}$ & $\mathbf{p}$ \\
\hline Model 1 & & & \\
sdLDL & 8.43 & $1.30-54.57$ & $0.025^{*}$ \\
Age & 7.30 & $0.89-59.73$ & 0.064 \\
Age & 11.80 & $1.59-87.62$ & $0.016^{\star}$ \\
Dyslipidemia & 4.87 & $0.89-26.51$ & 0.067 \\
ApoB/ApoA-I ratio & 2.98 & $0.19-45.79$ & 0.43 \\
Model 2 & & & \\
sdLDL & 10.55 & $1.80-61.73$ & $0.009^{*}$ \\
Age & 11.61 & $1.83-73.54$ & $0.009^{*}$ \\
Smoking & 11.96 & $1.71-83.81$ & $0.013^{*}$ \\
Dyslipidemia & 4.83 & $0.89-25.98$ & 0.067 \\
\hline
\end{tabular}

${ }^{*} \mathrm{p}<0.05$ significant

CI: Confidence Interval, PR: Prevalence Ratio, Apo: Apolipoprotein, sdLDL: Small Dense Low-Density Lipoprotein

when using an ApoB/ApoA-I ratio > 0.9, risk of PAD was 2 times higher. ${ }^{22}$ A study by Schmidt et al. showed that subjects with ApoB/ApoA-I ratio $\geq 0.9$ had a significantly increased risk of CVD for 6.6 years of follow-up (OR: 3.07; 95\% CI: 1.22-7.71). A greater risk of plaque in the femoral artery was also observed in subjects with an ApoB/ApoA-I ratio $\geq 0.9$ compared with subjects <0.9 (OR: $3.06 ; 95 \% \mathrm{CI}$ : 1.22-7.70). A study by Fowler et al. in 4470 males showed that there was an increased risk of PAD almost three times along with the increasing age (OR: 2.6; 95\% CI: 2.1-3.2). ${ }^{23}$ In this study there was an increased prevalence of PAD along with increasing age as follows: $10.6 \%$ increase of PAD prevalence at age of $65-69$ years (95\% CI: 9.1-12.0), 17.9\% increase at age of $70-74$ years (95\% CI: $16.0-19.8)$, and $23.3 \%$ increase at age of $75-79$ years (95\% CI: 20.6-25.9). ${ }^{24}$

Smoking is the most frequent risk factor for PAD. Nicotine causes vasoconstriction, and carbon monoxide from nicotine decreases the capacity of 
red blood cells to transport oxygen. Smoking cessation decreases the development of Intermittent Claudication (IC) and Claudication Limb Ischemia $(\mathrm{CLI}){ }^{25}$ Smoking is the strongest risk factor for PAD and shows a dose-response relationship. Overall, former smokers had a 2-fold significant risk of PAD compared with non-smokers for life, with a progressive reduction in risk of 5.4 (95\% CI: 2.4-11.9) was found in those who stopped smoking in a year before screening to 1.3 (95\% CI: 1.0-1.7) in those who last smoked at least 20 years earlier. ${ }^{24}$

The results of multivariate regression analysis in this study were similar to those of Rizzo et al. in 31 study subjects with PAD which reported that the presence of PAD was independently related with clinical and laboratory parameters tested, including age, obesity, smoking, diabetes, hypertension, family history of CVD, high TG, low HDL concentration, high $\mathrm{LDL}$ concentration, and elevated sdLDL. There was a significant relation with smoking (OR: $7.2,95 \% \mathrm{CI}$ : 1.6-32.3, $\mathrm{p}=0.0099$ ), hypertension (OR: $6.5 ; 95 \% \mathrm{CI}$ : 1.1-37.7, $p=0.0362$ ), DM (OR: 5.5; 95\% CI: 1.1-29.3; $p=0.0450)$ and increased concentration of sdLDL (OR: 6.7; 95\% CI: 1.1-45.1; $p=0.0497) .26$ Study by Yang et al. in 4716 study subjects with hypertension after adjustment of gender, age, and other cardiovascular risk factors reported that PAD was still related with smoking (OR: 1.65; 95\% CI: 1.18-2.29), history of stroke (OR: $1.50 ; 95 \% \mathrm{CI}: 1.12-2.00)$, serum uric acid (OR: 1.21; 95\% CI: 1.10-1.59); and TC (OR: 1.12; $95 \%$ CI: $1.10-1.59)^{7}$

The limitation of this study was no confirmation of the cause-effect relationship between sdLDL, ApoB/ApoA-I ratio, and other variables with the occurrence of PAD in hypertension patients due to the use of cross-sectional study design.

\section{CONCLUSION AND DISCUSSION}

sdLDL and ApoB/ApoA-I ratio were related to $P A D$. sdLDL, age, and smoking were independent variables of PAD in hypertension patients.

Further study with the case-control design was needed to obtain an odds ratio or with a cohort design to get hazard ratio to clarify the relations of sdLDL, ApoB/ApoA-I ratio, and other variables with the occurrence of PAD in hypertension patients.

\section{REFERENCES}

1. Peach G, Griffin M, Jones KG, Thomson MM, Hinchliffe RJ. Diagnosis and management of peripheral arterial disease. BMJ, 2012; 345: 1-8.
2. Sarkar T, Singh NP. Epidemiology and genetic of hypertension. J Association Physicians of India. 2015; 5: 61-69.

3. Bennet PC, Silverman S, Gill P. Hypertension and peripheral arterial disease. Journal of Hypertension, 2009; 23: 213-215.

4. Olin JW, Sealove B.. Peripheral arterial disease: Current insight into the disease and it diagnosis and management. Mayo Clin Proc, 2010; 7: 672-692.

5. Hennion RD, Siano KA. Diagnosis and treatment of peripheral arterial disease. Am Fam Physician. 2013; 5: 306-310.

6. Thiruvoipati T, Keilhorr CE, Amstrong E. Peripheral artery disease in patient with diabetes: Epidemiology, mechanism, and outcomes. Word J Diabetes. 2015; 7: 961-969.

7. Yang XM, Sun $K$, Zang W, Wu H, Zhang $H$, Hui RT. Prevalence of and risk factors for PAD in the patient with hypertension among Han Chinese. J Vasc Sur. 2007; 46: 296-302.

8. Thendria T, Toruan IL, Natalia D. Hubungan hipertensi dan penyakit arteri perifer berdasarkan nilai ankle brakial index. e J K I, 2014; 2: 37-44.

9. Gardner AW, Alaupovic P, Parker DE, Momtgomery PS, Elponda OL, Casanegra AI. Influence of peripheral arterial disease and statin therapy on apolipoprotein profile. Int J Vasc Med. 2013; 33: 1-16.

10. Xu D, Zou L, Xing Y, Hou L, Wei Y, Li J, Zhang J, et al. Diagnostic value of ankle brachial index in peripheral arterial disease: A metaanalysis. Canadian J Cardio. 2013; 29: 492-498.

11. Steinberg D, Witztum JL. Oxidaton specific epitopes are danger associated molecular pattern recognized by pattern recognation of innate immunnity. Circulation Resch, 2011; 2: 235-248.

12. Nikolic D, Katsiki N, Montalto G, Isenovic ER, Mikhailidis DP, Rizzo M. Lipoprotein subfraction in metabolic syndrome and obesity: Clinical significance and therapeutic approaches. ISSN 2072-6643. MDPI Nutrients. 2013; 3: 928-948.

13. Palazhy $S$, Kamath $P$, Vasudevan D. Estimation of small dense LDL particles using equations derived from routine lipid parameter as surrogate markers. Biochem Aral Biochem, 2014; 3: 1-5.

14. Kaneva AM, Potolisyana NN, Bojko ER, Odland JO. The Apoprotein B/Apoprotein A-1 as a potensial marker of plasma atherogenicity. Hindawi Publishing Corporation Disease Markers, 2015; 7: 1-7.

15. IvanovaEA, Myasoedova VA, Grechko AV, Orekhov AN.. Small dense low density as biomarker for atherosclerotic disease. Oxidative Med Cell Longevity. 2017; 1: 1-10.

16. DesplantieO, Ramnathan K, Daskalopoulou SS, Louisepilote ME, Khan NM. Can ApoBand ApoA-I ratio predict future cardiovascular risk pot acute coronary syndrome? A retrospective cohort study. J Clin Exp Cardiolog, 2016; 7: 5-17.

17. Shandu PK, Musaad SMA, Remaley AT. Bvehler HW, Ranne A. Lipoprotein biomarker and risk of 
cardiovascular disease: A Laboratory Medicine Best Practice (LMBP)systemic review. J Appl Lab Med. 2016; 2: 214-229.

18. Lima LM, Carvalho MG, Sabino AP, Mota AP, Fernandes $A D$, Osausa $M$. ApoB/ApoA-I ratio in central and peripheral arterial disease. Arg Bras Endocrinal Metab, 2007; 7: 1160-1165.

19. Jacomella V, Gerber PA, Mosimann K, Husman M, Thalhammer C, Wilkinson I, Berneis $\mathrm{K}$, et al. Small dense low density lipoprotein particles are associated with poop outcome after angiplasti in peripheral arterial disease. Plos One, 2014; 9: 1-5.

20. Li G, Wu H, Wu X, Cao Z, Tu Y, Ma Y, Wang W, et al.. Small dense low density lipoprotein-cholesterol and cholesterol ratio to predict arterial stiffness progression in normotensive subjects over a 5 years period. Lipid in Health and Disease, 2018; 17: 27.

21. Johansson L, Schmidt C. Increase ApoB/ApoA-I ratio is predictive of peripheral arterial disease in healthy 58 years old men during 8.9 years of follow-up. Angiology, 2009; 60: 539-545.

22. Schmidt C, Fagerberg B, Wikstarnd J, Hulthe J. ApoB/ApoA-1 ratio is related to femoral artery plaques and is predictive for future cardiovascular events in healthy men. Atherosclerosis, 2006; 189: 178-185.

23. Fowler B, Jamrozik K, Norman P, Allen Y. Prevalence of peripheral arterial disease: Persistence of excess risk in former smoker. Aust N Z J Public Health, 2002; 26: 219-24.

24. Muir RL. Peripheral arterial disease: pathophysiology, risk factors, disgnosis, treatment, and preventation. J Vasc Nurs, 2009; 27: 26-30.

25. Rizzo M, Pernice V, Berneis K. Atherogenic lipoprotein phenotype and LDL size and subclasses in patients with peripheral arterial disease. Atherosclerosis, 2008; 197: 237-241. 